\title{
Detection of Myocardial Ischemia With a Computer-Assisted 12-lead 24-hour ECG Monitoring System (EAGLE) in Patients With Suspected Unstable Angina
}

\author{
Satoshi Shimada, MD; Yuzo Hirota, MD; Haruhiko Onaka, MD; \\ Takayuki Mishima, MD; Shuji Suzuki, MD; Yoshihide Kawakami, MD; \\ Yasuhiko Sakai, MD; Yoshio Kita, MD; Keishiro Kawamura, MD
}

\begin{abstract}
This study was undertaken to evaluate the diagnostic value of a new device, the 'EAGLE' computer-assisted multiple-lead long-term electrocardiography (ECG) monitoring and analyzing system, in patients with suspected unstable angina, and to compare the results with the Holter monitor. A total of 101 patients with a history of suspected unstable angina underwent a simultaneous 24-h examination with the EAGLE and 2-channel Holter monitors. The diagnosis of unstable angina was established in 70 patients: 41 had significant organic stenosis, and 29 had coronary spasm. Ischemic ST deviations were detected 229 times in 44 patients (62.9\%) with the EAGLE system and 101 times in 20 patients $(28.6 \%)$ with the Holter monitor. The sensitivity of myocardial ischemia in unstable angina with the EAGLE system was significantly higher than that with Holter monitor (62.9 vs $28.6 \%, \mathrm{p}<0.05)$. The difference of sensitivity was due mainly to the low detection rate of the Holter monitor for asymptomatic myocardial ischemia (EAGLE vs Holter ; 187 times vs 72 times) and myocardial ischemia in the infero-posterior area in patients with organic stenosis (30 times vs none). It is concluded that the EAGLE system is a sensitive tool for the diagnosis of unstable angina in patients without significant ECG changes, and an excellent tool for evaluating silent myocardial ischemia or myocardial ischemia of the infero-posterior area. (Jpn Circ J 1998; 62: 586-591)
\end{abstract}

Key Words: Computer-assisted 12-lead ECG monitor; Electrocardiography; Holter monitor; Myocardial ischemia; Unstable angina

$\mathbf{E}$ stablishing the diagnosis of unstable angina is often difficult in patients with a history of suspected unstable angina but without significant electrocardiogram (ECG) changes on admission. Traditionally, the documentation of chest pain with reversible ischemic ECG change has been used for the diagnosis in such patients. Because it is difficult to record a 12-lead ECG while a patient is experiencing chest pain, transient ST segment deviations detected by Holter monitoring have been accepted as an accurate and reliable alternative to the 12lead ECG 1,2

It is known that $50-80 \%$ of ischemic ST segment changes are not associated with angina pain in patients with chronic stable angina 3,4 and silent myocardial ischemia has been reported to be $70-90 \%$ of the total myocardial ischemia in unstable angina, 5 ,6 The presence of silent myocardial ischemia has been recognized as an important factor in prognosis? ${ }^{7} 8$ Therefore, the detailed monitoring of myocardial ischemia is important not only for establishing the diagnosis but also for clinical decision-making.

(Received July 31, 1997; revised manuscript received February 25, 1998; accepted March 13, 1998)

Third Division, Department of Internal Medicine, Osaka Medical College, Takatsuki, Japan

This study was supported by grants from the Fellows' Association of the Japanese Society of Internal Medicine, Fukuda Denshi Ltd, and Tanabe Seiyaku Co. Ltd

Mailing address: Yuzo Hirota, MD, Third Division, Department of Internal Medicine, Osaka Medical College, 2-7 Daigaku-cho Takatsuki-City, Osaka, 569-8686, Japan
Compared to the standard 12-lead ECG, only 2 leads are available with the conventional Holter monitor. When the long-term 12-lead standard ECG monitor is used, the diagnostic value and the detection rate of myocardial ischemia, either symptomatic or silent, should be much higher compared to the Holter monitor? We have developed a new device, the computer-assisted multiple-lead long-term ECG monitoring and analyzing system (Easy Analysis by Graphics of Long-term ECG system: EAGLE). The purpose of this study was to evaluate the diagnostic value of the EAGLE system in patients with a history of suspected unstable angina, by comparing the detection rate of symptomatic and silent myocardial ischemia between the EAGLE and Holter monitors.

\section{Methods}

Patient Population and Study Protocol

Two hundred and one patients were admitted to the Department of Internal Medicine between July 1991 and December 1994 under the diagnosis of suspected unstable angina. The study population consisted of 101 patients who underwent simultaneous EAGLE and Holter monitoring for $24 \mathrm{~h}$ after admission. They had a clinical history of suspected angina but had no documented ECG changes. Among these patients, 69 were male, and the mean age was 68 years (range, $37-80$ ).

For the 24-h period of simultaneous EAGLE and Holter monitoring, the patients were kept in bed with an intravenous heparin infusion. Medications from the outpatient 


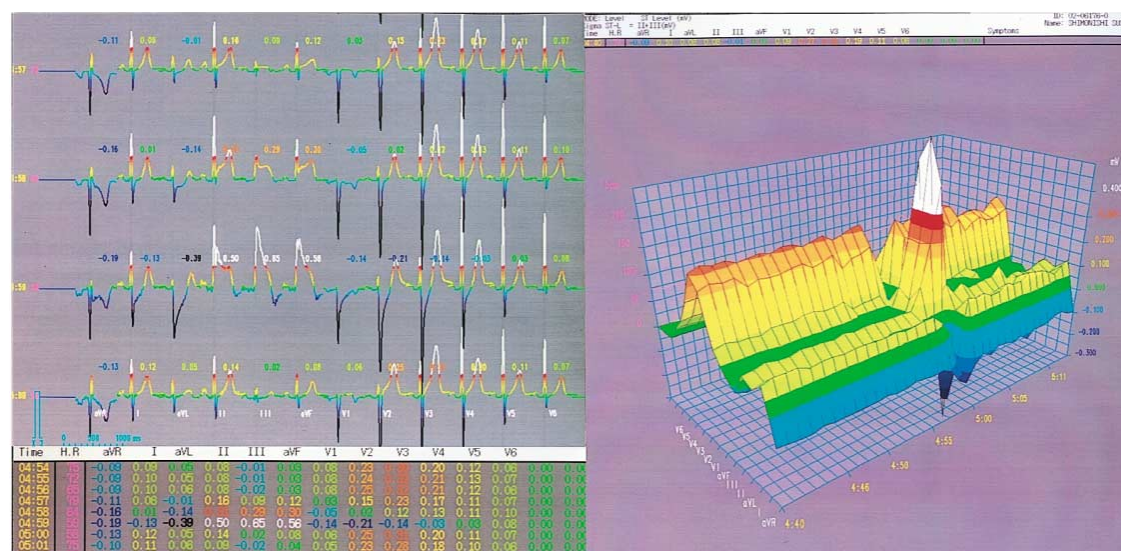

Fig 1. ECG changes detected by the EAGLE system during an episode of variant angina in a 56-year-old male with vasospastic angina. Marked ST elevations in II, III and aVF with reciprocal ST depressions were observed for $4 \mathrm{~min}$ from $4.57 \mathrm{~h}$ (left upper panel). These ST deviations are digitally displayed in the left lower panel. ST deviations are displayed in the 3-dimensional frame work of the $\mathrm{X}$-axis as leads, the $\mathrm{Y}$-axis as ST deviations and the Z-axis as time (righthand panel).

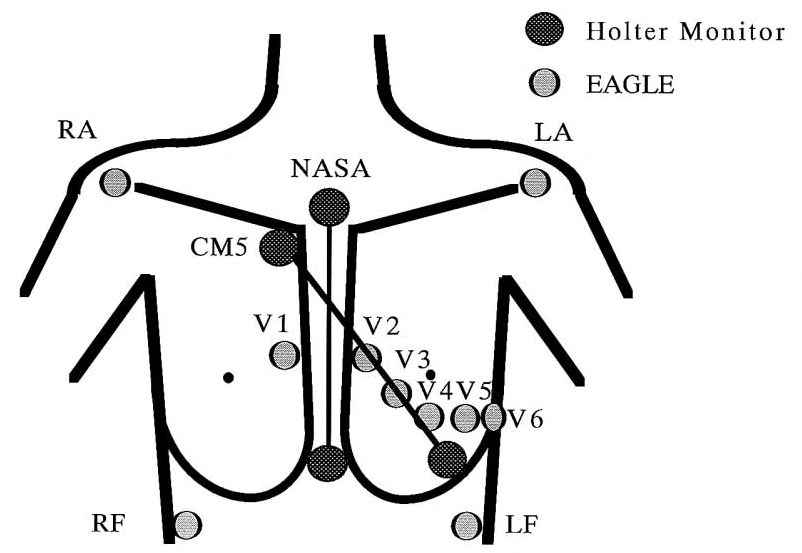

Fig 2. Electrode positions used in the study. (Open circles) Electrode positions used for the EAGLE system. (Closed circles) Electrode positions used for the Holter monitor.

clinic or referral doctors were continued, and oral aspirin $(81 \mathrm{mg})$ also given. When a patient complained of chest symptoms, a 12-lead ECG was printed out from the EAGLE system, $0.3-0.6 \mathrm{mg}$ of sublingual nitroglycerin was given, and an intravenous isosorbide dinitrate infusion was started at the rate of $2 \mathrm{mg} / \mathrm{h}$. When the symptoms continued or recurred, emergency coronary cineangiography was performed. The patients whose monitoring was terminated prematurely because of mechanical trouble or clinical aggravation were not included in the study.

\section{Monitoring Systems}

The EAGLE system is a portable, programmable microprocessor-based device that can acquire, store and analyze standard 12-lead and 3-Frank lead ECG data. Using an ML-5000 (Fukuda Denshi, Tokyo, Japan), ECG waveforms are collected for $15 \mathrm{sec}$ out of every $1 \mathrm{~min}$ period, with premature ventricular contractions and electrical noise being discarded. An averaged QRST complex, free from artifact, is sent to the work station (SPARK 2EX plus, SUN; Fujitsu, Tokyo, Japan), and can be stored continuously for up to $48 \mathrm{~h}$ in a photomagnetic disk. Data analysis is done using the work station. Data can be displayed as the standard 12-lead analog wave forms, or digitally at measured points of the ST segment of all 12 leads. ST segment trend data can also be displayed 3-dimensionally using computer graphics (Fig 1). The frequency response of this system is linear between 0.05 and $100 \mathrm{~Hz}$.
A Fukuda SM-28 2 channel recording device was used for the Holter monitor. CM5 and modified aVF leads were recorded, with 2 exploring electrodes in the mid-portion between $\mathrm{V}_{4}$ and $\mathrm{V}_{5}$ and over the lower sternum, 2 negative electrodes over the manubrium, and the ground electrode over the right lower part of the chest. A Fukuda DCM$9000 \mathrm{H}$ analysis device was used for data analysis. The lead positions for the EAGLE system and Holter monitor used in this study are shown in Fig 2. The frequency response of this system is linear between 0.5 and $40 \mathrm{~Hz}$.

\section{Data Analysis}

The ST changes were measured at $80 \mathrm{msec}$ after the $\mathrm{J}$ point with both systems. To avoid false diagnosis of ST deviations, control ECGs were recorded with each postural position at the beginning of the monitoring process. When positional ST deviations were detected, they were differentiated from ischemic ST deviations by observing the QRS changes seen during the specific postural position. A greater than $0.1 \mathrm{mV}$ horizontal or down slope depression or a greater than $0.1 \mathrm{mV}$ elevation in more than 2 leads for more than 1 min was judged as positive with the EAGLE system, and a greater than $0.1 \mathrm{mV}$ horizontal or down slope depression or a greater than $0.1 \mathrm{mV}$ elevation of more than 1 min duration, which appeared and disappeared gradually, was considered positive with the Holter monitor. The total count of ST deviations was compared and the usefulness for the diagnosis of unstable angina was evaluated. The characteristics of the ST deviations of each device were also evaluated to clarify the difference in diagnostic value. In order to evaluate the ST change (either elevation or depression) and leads corresponding to the myocardial area (I, $\mathrm{aV}_{\mathrm{L}} / \mathrm{II}, \mathrm{III}, \mathrm{aVF} / \mathrm{V}_{1}-\mathrm{V}_{6}$ ) in the EAGLE system, all ST deviations were classified: when ST depression alone was seen, it was counted as ST depression; when ST depression and elevation were seen simultaneously it was counted as ST elevation.

\section{Coronary Cineangiography}

Coronary cineangiography was performed in 97 patients using the standard Judkins technique. It was done within 48 $\mathrm{h}$ of admission in 8 patients who had repeated episodes of myocardial ischemia during the $24-\mathrm{h}$ monitoring period. Oral and/or intravenous anti-anginal medications were continued during the procedure. The cineangiography was performed electively for the remaining 89 patients under the conditions of a 12-h fast and without premedication. When the initial cineangiograms showed significant 
Table 1 Patient Profile

\begin{tabular}{|c|c|c|c|c|c|}
\hline & $\begin{array}{c}U A \\
(n=70)\end{array}$ & $\begin{array}{c}\text { Organic } \\
(n=41)\end{array}$ & $\begin{array}{c}V S A \\
(n=29)\end{array}$ & $\begin{array}{c}C P S \\
(n=31)\end{array}$ & pvalue \\
\hline Age (years) & $62.1 \pm 6.5$ & $63.5 \pm 6.8$ & $60.0 \pm 6.2$ & $58.6 \pm 8.6$ & \\
\hline $\operatorname{Sex}(M: F)$ & $50: 20$ & $28: 13$ & $22: 7$ & $18: 13$ & \\
\hline \multicolumn{6}{|c|}{ Coronary risk factor } \\
\hline$H T$ & $42(60 \%)$ & $27(66 \%)$ & $15(52 \%)$ & $8(26 \%)$ & $p=0.002$ \\
\hline$D M$ & $20(29 \%)$ & $13(32 \%)$ & $7(24 \%)$ & $4(13 \%)$ & \\
\hline$H L$ & $23(33 \%)$ & $17(42 \%)$ & $6(21 \%)$ & $2(6 \%)$ & $p=0.005$ \\
\hline$S M$ & $47(67 \%)$ & $26(63 \%)$ & $21(72 \%)$ & $12(39 \%)$ & $p=0.008$ \\
\hline ECG abnormality & $32(46 \%)$ & $24(59 \%)$ & $8(27 \%)$ & $8(26 \%)$ & $p=0.059$ \\
\hline \multicolumn{6}{|l|}{ Coronary anatomy } \\
\hline Not performed & $1(1 \%)$ & $1(2 \%)$ & $0(0 \%)$ & $3(10 \%)$ & \\
\hline$O V D$ & $24(34 \%)$ & $0(0 \%)$ & $24(83 \%)$ & $28(90 \%)$ & \\
\hline $1 V D$ & $19(27 \%)$ & $15(29 \%)$ & $4(13 \%)$ & $0(0 \%)$ & \\
\hline $2 V D$ & $14(20 \%)$ & $13(34 \%)$ & $1(3 \%)$ & $0(0 \%)$ & \\
\hline $3 V D$ & $12(17 \%)$ & $12(27 \%)$ & $0(0 \%)$ & $0(0 \%)$ & \\
\hline
\end{tabular}

UA; unstable angina; VSA, vasospastic angina; CPS, chest pain syndrome; HT, hypertension; DM, diabetes mellitus; HL, hyperlipidemia; SM, smoking; VD, vessel disease. *p value: between UA and CPS.

Table 2 Detection of ST Deviations With the EAGLE and Holter Systems in Patients With Unstable Angina or Chest Pain Syndrome

\begin{tabular}{|c|c|c|c|c|}
\hline & $U A(n=70)$ & $O S(n=41)$ & $V S A(n=29)$ & $C P S(n=31)$ \\
\hline$E A G L E$ & $44(62.9 \%)$ & $24(58.5 \%)$ & $20(68.9 \%)$ & $5(16.7 \%)$ \\
\hline Holter & $20(28.6 \%)]^{* *}$ & $9(22.0 \%)]^{* *}$ & $11(37.9 \%)]^{*}$ & $2(6.7 \%)$ \\
\hline
\end{tabular}

UA, unstable angina; OS, organic stenosis; VSA, vasospastic angina; CPS, chest pain syndrome. ${ }^{* * p}<<0.01,{ }^{*} p<0.05$.

Table 3 Diagnostic Value of the EAGLE and Holter Systems for Unstable Angina

$\left.\begin{array}{lcccc}\hline \hline & \text { Sensitivity } & \text { Specificity } & \text { Positive PV } & \text { Negative PV } \\ \hline \text { EAGLE } & 62.9 \% \\ \text { Holter } & 28.6 \%\end{array}\right] * \begin{array}{lcc}* \\ \end{array}$

$P V$, predictive value. ${ }^{*} p<0.01$.

organic stenosis ( $>75 \%$ luminal narrowing), the cineangiography was repeated following an intravenous isosorbide dinitrate injection $(2-3 \mathrm{mg})$. An ergonovine provocation test ${ }^{10}$ was performed when significant stenosis was not observed with the initial cineangiogram.

\section{Diagnostic Criteria of Unstable Angina}

In those patients with a suspected history, the diagnosis of unstable angina was made when one of the following three criteria of myocardial ischemia was met: (i) the documentation of significant $(>0.1 \mathrm{mV})$ reversible ST deviations with angina pain at rest after admission; (ii) the presence of significant organic stenosis in at least one major epicardial branch demonstrated by more than $75 \%$ luminal narrowing after an intravenous isosorbide dinitrate injection; or (iii) spontaneous or ergonovine-induced focal artery spasm of greater than $90 \%$ luminal narrowing in association with chest pain and ECG changes.

\section{Analysis of the Data and Statistical Analysis}

Sensitivity was defined as the number of true positives divided by the total number of true positives. Specificity was defined as the number of true normals divided by the total number of normals. Positive predictive value was defined as the number of true positives divided by the sum of true positives and false positives. Continuous data are expressed as mean $\pm \mathrm{SD}$, and were compared with Student's t-test for unpaired data. Quantitative features were expressed as percentages and were analyzed with the Chisquare test. The Fisher exact test was also applied when appropriate. A p value less than 0.05 was considered significant.

\section{Results}

Study Population

The clinical characteristics of the 101 patients are shown in Table 1 . Seventy of the 101 patients $(69.3 \%)$ were diagnosed as having unstable angina. The etiology of unstable angina was related to severe organic stenosis in 41 patients, and the symptoms were considered to be mediated by significant coronary spasm in the other 29 patients. The etiology of chest pain was not related to coronary artery disease in the 31 patients not diagnosed as having unstable angina; these patients were classified as having chest pain syndrome. No significant differences regarding age and gender were seen between the patients with unstable angina and those with chest pain syndrome. Coronary risk factors were more frequently seen in patients with unstable angina, such as hypertension [42 of $70(60.0 \%)$ vs 8 of $31(25.8 \%)$, $\mathrm{p}=0.002]$, hyperlipidemia [23 $(32.9 \%)$ vs $2(6.5 \%), \mathrm{p}=$ 0.005 ] and smoking [47 (67.1\%) vs $12(38.7 \%), \mathrm{p}=0.008]$.

Detection of ECG Changes in the Study Population and Diagnostic Value of the EAGLE and Holter Systems

The detection rates of the ST changes with the EAGLE 
Table 4 Characteristics of ST Deviations in Patients With Unstable Angina ( $n=70)$

\begin{tabular}{lcc}
\hline \hline & EAGLE & Holter \\
\hline Total patients & $44(62.9 \%)$ & $20(28.6 \%)$ \\
Total no. ST deviations detected & 229 & 101 \\
Symptoms & & \\
$\quad$ Symptomatic & $42(18.3 \%)$ & $29(28.7 \%)$ \\
$\quad$ Asymptomatic & $187(81.7 \%)$ & $72(71.3 \%)$ \\
ST change & & \\
$\quad$ Elevation & $142(62.0 \%)$ & $76(75.2 \%)$ \\
$\quad$ Depression & $87(38.0 \%)$ & $25(24.8 \%)$ \\
Leads & & \\
$I,{ }_{\text {a }}$ & $9(3.9 \%)$ & NASA $55(54.5 \%)$ \\
II, III, aVF & $150(65.5 \%)$ & CM5 $46(45.5 \%)$ \\
$V_{I}-V_{6}$ & $70(30.6 \%)$ & \\
\hline
\end{tabular}

Table 5 Characteristics of ST Deviations in Patients With Organic Stenosis $(n=41)$

\begin{tabular}{lcc}
\hline \hline & EAGLE & Holter \\
\hline Total patients & $24(58.5 \%)$ & $9(22.0 \%)$ \\
Total no. ST deviations detected & 68 & 18 \\
Symptoms & & \\
$\quad$ Symptomatic & $9(13.2 \%)$ & $1(5.6 \%)$ \\
$\quad$ Asymptomatic & $59(86.8 \%)$ & $17(94.1 \%)$ \\
ST change & & \\
Elevation & $9(13.2 \%)$ & $0(0 \%)$ \\
Depression & $58(86.8 \%)$ & $18(100 \%)$ \\
Leads & $3(4.4 \%)$ & \\
$I$, aV & & \\
II, III, aVF & $27(39.7 \%)$ & CMSA $0(0 \%)$ \\
$V_{I}-V_{6}$ & $38(55.9 \%)$ & \\
\end{tabular}

Table 6 Characteristics of ST Deviations in Patients With Vasospastic Angina (n=29)

\begin{tabular}{lcc}
\hline \hline & EAGLE & Holter \\
\hline Total patients & $20(68.9 \%)$ & $11(37.9 \%)$ \\
Total no. ST deviations detected & 161 & 83 \\
Symptoms & & \\
$\quad$ Symptomatic & $33(20.5 \%)$ & $28(33.7 \%)$ \\
$\quad$ Asymptomatic & $128(79.5 \%)$ & $55(66.3 \%)$ \\
ST change & & \\
$\quad$ Elevation & $133(82.6 \%)$ & $76(91.6 \%)$ \\
$\quad$ Depression & $28(17.4 \%)$ & $7(8.4 \%)$ \\
Leads & & \\
$\quad$ I, aV & $6(3.7 \%)$ & NASA $55(66.3 \%)$ \\
II, III, aVF & $123(76.4 \%)$ & $C M 528(33.7 \%)$ \\
$V_{I}-V_{6}$ & $32(19.9 \%)$ &
\end{tabular}

and Holter systems are shown in Table 2. Ischemic ST deviations were detected in 44 patients $(62.9 \%)$ with the EAGLE system and in 20 patients $(28.6 \%)$ with the Holter monitor among the 70 patients with unstable angina. The detection rate did not differ significantly between the patients with organic stenosis and those with vasospastic angina. While the EAGLE system showed asymptomatic ST deviations in 5 patients with chest pain syndrome, ECG changes were observed in 2 patients with the Holter system (ns).

The EAGLE system was superior in diagnostic sensitivity for unstable angina $(62.9 \%$ vs $28.6 \%, \mathrm{p}<0.01)$ in patients without significant ECG change at rest, but no significant differences were observed between the two systems in specificity, positive predictive or negative predictive values (Table 3 ).
ST deviations were detected 229 times in 44 patients with the EAGLE system and 101 times in 20 patients with the Holter system (Table 4). Most of the ST deviations were not associated with angina $(81.7 \%$ with EAGLE and $71.3 \%$ with Holter, respectively). With the EAGLE system, about $2 / 3$ of ST deviations were ST elevation $(62.0 \%)$, and also about $2 / 3$ were located in the inferior areas (II, III, $\mathrm{aVF} ; 65.5 \%), 30 \%$ were in the antero-septal area $\left(\mathrm{V}_{1}-\mathrm{V}_{6}\right)$ and only $4 \%$ were in the lateral area $\left(\mathrm{I}, \mathrm{aV}_{\mathrm{L}}\right)$. With the Holter system, about half of the ST deviations were detected with modified aVF $(54.5 \%)$, and the other half were detected with CM5 (45.5\%).

There were prominent differences in the ST changes between the patients with organic stenosis and those with vasospastic angina. Of the 41 patients with organic stenosis, ST deviations were detected 68 times in 24 patients with the EAGLE system, and 18 times in 9 patients with the Holter system. While ST elevations were observed 9 times with the EAGLE system, these were not detected with the Holter monitoring. Only ST depressions were detected with the Holter system in this group, and these were localized at CM5 (Table 5).

Among the 29 patients with vasospastic angina, ST deviations were detected 161 times in 20 patients with the EAGLE system, and 83 times in 11 patients with the Holter system. In this group, 133 of the $161(82.6 \%)$ ST changes detected with the EAGLE system were ST elevations, and were most frequently localized in inferior leads [in II, III, $\mathrm{aVF} 123 / 166(76.4 \%)]$. In contrast to the organic stenosis group results, this $\mathrm{ST}$ deviation could be detected relatively well $(66.3 \%)$ in modified a $\mathrm{VF}_{\mathrm{F}}$ with the Holter system (Table 6).

\section{Discussion}

\section{Clinical Spectrum of Unstable Angina}

The degree of unstable angina can vary widely, from a new onset of exertional angina to impending myocardial infarction. While emergency coronary angiography and revascularization procedures are necessary for patients with prolonged chest pain and ECG changes ${ }^{11}$ or hemodynamic instabilities, it is often difficult to establish an accurate diagnosis in patients with only a suspected history and without significant ECG changes on admission. Patients with other than coronary artery disease are estimated to be $20-60 \%$ of all patients who are admitted under the diagnosis of possible unstable angina ${ }^{12,13}$ The ECG documentation of ischemic ST changes is crucial for the diagnosis of these patients.

\section{Evaluation of Symptomatic and Silent Myocardial Ischemia}

The significance of the ST deviations detected with the Holter monitor as an indicator of true myocardial ischemia has been validated with simultaneous recordings of hemodynamic $^{14}$ and radionuclide imaging data 15 These ischemic ST changes are frequently seen in patients with coronary artery disease in general. ${ }^{16-18}$ In patients with unstable angina, $70-90 \%$ of ST changes have been reported to be not associated with angina symptoms 5,6 These evaluations confirm that the extent of coronary artery disease and inhospital morbidity and mortality are worse in patients with silent myocardial ischemia than in patients without it ${ }^{5-8}$

In the present study, ischemic ST deviations were detected in only $62.9 \%$ of the unstable angina patients with 
the EAGLE system and in $28.6 \%$ with the Holter system. These relatively low detection rates are thought to be due to the study population; most of whom were Braunwald severity class I or II 19 Patients with refractory angina or who were hemodynamically compromised were not included in the present study because of the rquirement for emergency therapy. Only 8 of the 70 patients in the study required urgent coronary angiography; the majority of the other patients were stabilized with bed rest and the administration of oral aspirin and intravenous heparin. While ST deviations were detected 229 times in 44 patients $(62.9 \%)$ with the EAGLE system, they were seen only 101 times in 20 patients $(28.6 \%)$ with the Holter system. Our results have clarified several important limitations of the Holter monitor in regard to the diagnosis of myocardial ischemia. In patients with organic stenosis, ST changes were detected only 18 times with the Holter system, while 68 ST changes were documented with the EAGLE system. Eight episodes of chest discomfort with ST deviation recorded with the EAGLE system were not associated with ST changes with the Holter system. Among the patients with organic stenosis, whose ST deviations were less prominent, 18 of the 38 changes were seen in CM5, and 27 episodes seen in II, III and $\mathrm{aVF}$ with the EAGLE system could not be detected in modified aVF with the Holter system. In contrast among the patients with vasospastic angina, whose ST deviations were more prominent, about $50 \%$ of the ST elevations seen in II, III and $\mathrm{aVF}$ were detected in modified $\mathrm{aVF}$, and 28 of 32 episodes detected in $\mathrm{V}_{1}-\mathrm{V}_{6}$ could be detected in CM5. These findings may be due to the choice of lead position (NASA) and the effect of amplitude distortion in the low frequency component of the Holter monitor, which has this distortion between 0.12 and $0.5 \mathrm{~Hz}$. On the other hand, the amplitude distortion was not detected in the EAGLE system and the frequency response was linear between 0.05 and $100 \mathrm{~Hz}$. These observations suggest that the wellaccepted diagnostic criteria of myocardial ischemia with the Holter monitor are less sensitive for the detection of ischemic ST changes and especially so for the diagnosis of subendocardial ischemia of the infero-posterior area when the patient is at rest.

\section{Other New Devices}

The standard 2-channel Holter monitor is used widely, but it has been suggested that some ischemic episodes can be missed by 2-lead systems. ${ }^{20,21}$ After the introduction of a third channel, the usefulness of various new lead positions was evaluated, with unsatisfactory results ${ }^{22-24}$ Tanabe et al produced a 9-lead Holter monitor using switching methods ${ }^{25}$ and Dower et al reported on the efficacy of deriving a 12-lead ECG from 4 electrodes ${ }^{26}$ In 1987 , Krucoff et al introduced a computer-assisted 12-lead electrocardiographic monitor (Mortara ELI-100/STM), ${ }^{27}$ which provided multiple ECG acquisition and real-time analyses of the ST segment. This system was used for the noninvasive detection of reperfusion or silent coronary reocculusion after thrombolysis therapy in patients with acute myocardial infarction, ${ }^{28}$ and for the detection of silent myocardial ischemia? That system is similar to the EAGLE system, and is superior for the real-time analysis of the ST segment. The memory capacity of the Mortara system is relatively small, however, which limits the storage of QRST samples to only 125, which is not suitable for longterm monitoring. The ECG waveform is a real-time waveform, and artifact cannot be avoided. The 24-h recording of
3 Frank leads and the mathematical reconstruction of the standard 12-lead ECG from the Frank leads has been reported recently; ${ }^{29,30}$ however, the clinical significance of this has not been validated yet.

\section{Study Limitation and Clinical Implications}

Conditions other than myocardial ischemia also cause transient ST changes. The false-positive exercise test is a well-known phenomenon among patients receiving digitalis $^{31}$ and in middle aged females ${ }^{32}$ Postural changes, hyperventilation and the Valsalva maneuver are also factors in transient ST-T abnormalities ${ }^{3}$ Myocardial ischemia in the posterior wall of the left ventricle is difficult to detect with a standard 12-lead ECG ${ }^{34}$ Considering these factors, there are certain limitations in using ST-T changes for the detection of myocardial ischemia. The incidence of transient nonischemic ST changes differs among study populations, and is low among patients with known coronary artery disease. With the diagnostic criteria used in the present study (ie, $>0.1 \mathrm{mV}$ ST deviations in 2 leads with the EAGLE system and $>0.1 \mathrm{mV}$ ST deviations of gradual appearance and disappearance with the Holter system), the ST deviations in patients with unstable angina are thought to be due to myocardial ischemia. However, these changes were observed in 5 patients with the EAGLE system and in 2 patients with the Holter system among 31 patients with chest pain syndrome. Considering this, the detection of myocardial ischemia will be difficult when employing more strict criteria, and false positives will be increased when looser criteria, such as a greater than $0.05 \mathrm{mV} \mathrm{ST}$ deviation, are used. The relatively high detection rate [83/161 (51.6\%)] of the Holter system compared with the EAGLE system in the patients with vasospastic angina shows that the Holter system is a good tool for establishing the diagnosis, as recommended by the ACC/AHA Task Force 35 However, the low detection rate [18/68 (26.5\%)] with the Holter system in patients with organic stenosis indicates that myocardial ischemia should be reevaluated with more sophisticated new devices in future.

\section{References}

1. Schang SJ, Papine CJ: Transient asymptomatic ST segment depression during daily activity. Am J Cardiol 1977; 39: 396-402

2. Deanfield JE, Shea M, Ribiero P, de Landsheere CM, Wilson RA, Horlock P, et al: Transient ST-segment depression as a marker of myocardial ischemia during daily life. Am J Cardiol 1984; 54: $1195-1200$

3. Nabel EG, Barry J, Rocco MB, Campbell S, Mead K, Fenton T, et al: Variability of transient myocardial ischemia in ambulatory patients with coronary artery disease. Circulation 1988; 78: 60-67

4. Stern S, Gavish A, Weisz G, Benhorin J, Keren A, Tzivoni D: Characteristics of silent and symptomatic myocardial ischemia during daily activities. Am J Cardiol 1988; 61: 1223-1228

5. Gottlieb SO, Weisfeldt MD, Ouyang P, Mellits E, Gerstenblith G: Silent ischemia as a marker for early unfavorable outcomes in patients with unstable angina. N Engl J Med 1986; 314: 1214-1219

6. Nademanee K, Intarachot V, Josephson MA, Rieders D, Mody FV, Singh BN: Prognostic significance of silent myocardial ischemia in patients with unstable angina. J Am Coll Cardiol 1987; 10: 1-9

7. Langer A, Freeman MR, Armstrong PW: ST segment shift in unstable angina: Pathophysiology and association with coronary anatomy and hospital outcome. J Am Coll Cardiol 1989; 13: 1495-1502

8. Bugiardini R, Borghi A, Pozzati A, Ruggeri A, Puddu P, Maseri A: Relation of severity of symptoms to transient myocardial ischemia and prognosis in unstable angina. J Am Coll Cardiol 1995; 25: $597-604$

9. Thompson RC, Mackey DC, Lane GE, Brackshear JL, Shine TS, Evener MK, et al: Improved detection of silent cardiac ischemia with a 12-lead portable microprocessor-driven real-time electrocardiographic monitor. Mayo Clin Proc 1995; 70: 434-442 
10. Onaka H, Hirota Y, Shimada S, Kita Y, Sakai Y, Kawakami Y, et al: Clinical observation of spontaneous anginal attacks and multivessel spasm in variant angina pectoris with normal coronary arteries: evaluation by 24-hour 12-lead electrocardiography with computer analysis. J Am Coll Cardiol 1996; 27: 38-44

11. Braunwald E, Jones RH, Mark DB, Brown J, Brown L, Cheitlin MD, et al: Diagnosing and managing unstable angina. Circulation 1994; 60: $613-622$

12. Duncan B, Fulton M, Morrison SL, Lutz W, Donald KW, Kerr F, et al: Prognosis of new and worsening angina pectoris. Br Med J 1976; 1: $981-985$

13. van Miltenburg-van Zijl AJM, Simoons ML, Veerhoek RJ, Bossuyt PM: Incidence and follow-up of Braunwald subgroups in unstable angina pectoris. J Am Coll Cardiol 1995; 25: 1286-1292

14. Chierchia S, Lazzari M, Freedman B, Brunelli C, Maseri A: Impairment of myocardial perfusion and function during painless myocardial ischemia: J Am Coll Cardiol 1983; 1: 924-930

15. Tamaki N, Yasuda T, Moore RH, Gill JB, Boucher CA, Hutter AM $\mathrm{Jr}$, et al: Continuous monitoring of left ventricular function by an ambulatory radionuclide detector in patients with coronary artery disease. J Am Coll Cardiol 1988; 12: 669-679

16. Rocco MB, Nabel EG, Campbell S, Goldman L, Barry J, Mead K, et al: Prognostic importance of myocardial ischemia detected by ambulatory monitoring in patients with stable coronary artery disease. Circulation 1988; 78: $877-884$

17. Ouyang P, Chandra NC, Gottlieb SO: Frequency and importance of silent myocardial ischemia identified with ambulatory electrocardiographic monitoring in the early in-hospital period after acute myocardial infarction. Am J Cardiol 1990; 65: 267-270

18. Deedwania PC, Carbajal EV: Silent ischemia during daily life is an independent predictor of mortality in stable angina. Circulation 1990; 81: 748-756

19. Braunwald E: Clasification of unstable angina. Circulation 1989; 80: $410-414$

20. Krucoff MW: Poor performance of leads V5 in single- and dualchannel ST-segment monitoring during coronary occlusion. $J$ Electrocardiogr 1988; 21: 530-534

21. Mirvis DM, Berson AS, Goldberger AL, Green CS, Heger JJ, Hinohara T, et al: Instrumentation and practice standards for electrographic monitoring in special care units. Circulation 1988; 79: 464-471

22. Racine N, Ripley R, Ramsay J, Silberberg J, Sami MH: Holter monitor recording for the detection of myocardial ischemia: validation of a new recorder and chest lead positions. Can J Cardiol 1992; 8: $465-468$

23. Shandling AH, Bernstein SB, Kennedy HL, Ellestad MH: Efficacy of three-channel ambulatory electrocardiographic monitoring for the detection of myocardial ischemia. Am Heart J 1992; 123: 310-316

24. Lanza GA, Mascellanti M, Placentino M, Lucente M, Crea F, Maseri A: Usefulness of a third Holter lead for detection of myocardial ischemia. Am J Cardiol 1994; 74: 1216-1219

25. Tanabe T, Yoshioka K, Goto Y: Nine-lead Holter monitoring using a lead-switching technique for the detection of ischemic ST changes. Jpn Circ J 1992; 56: 1221 - 1228

26. Dower GE, Yakush A, Nazzal SB, Jutzy RV, Ruiz CE: Deriving the 12-lead electrocardiogram from four (EASI) electrodes. $J$ Electrocardiol 1988; 21(Suppl): S182-S187

27. Krucoff MW, Pope JE, Bottner RK, Renzi RH, Wagner GS, Kent KM:Computer-assisted ST-segment monitoring: Experience during and after brief coronary occlusion. J Electrocardiol 1987; 21(Suppl): S15-21

28. Krucoff MW, Croll MA, Pope JE, Granger CB, O'Connor CM, Sigmon KW, et al: Continuous 12-lead ST-segment recovery analysis in the TAMI 7 study: Performance of a noninvasive method for real-time detection of failed myocardial reperfusion. Circulation 1993; 88: 437-446

29. Weyne AE, De Buyzere-ML, Bauwens FR, Clement DL: Assessment of myocardial ischemia by 12-lead electrocardiography and Frank vector system during coronary angioplasty: value of a new orthogonal lead system for quantitative ST segment monitoring. $J$ Am Coll Cardiol 1991; 18: 1704-1710

30. Lundin P, Eriksson SV, Fredrikson M, Rehnqvist N: Prognostic information from on-line vector cardiography in unstable angina pectoris. Cardiology 1995; 86: 60-66

31. Kawai C, Hultgren HN, Calif PA: The effect of digitalis upon the exercise electrocardiogram. Am Heart J 1964; 68: 409-420

32. Cumming GR, Dufresne C, Kich L, Samm J: Exercise electrocardiogram patterns in normal women. Br Heart J 1973; 35: 1055-1061

33. Bertlet BD, Boyette AF, Hofmann CA, Pepine CJ, Hill JA: Prevalence of pseudoischemic ST-segment changes during ambulatory electrocardigraphic monitoring. Am J Cardiol 1992; 70: $818-820$

34. Boden W, Kleiger R, Gibson R, Schwartz D, Schchtman K, Capone $\mathrm{R}$, et al: Electrocardiographic evolution of posterior acute myocardial infarction: importance of early precordial ST segment depression. Am J Cardiol 1987; 59: 782-787

35. Knoebel SB, Grawford MH, Dunn MI, Fisch C, Forrester JS, Hutter AM Jr, et al: Guidelines for ambulatory electrocardiography: A report of the American College of Cardiology/American Heart Association Task Force on assessment of diagnostic and therapeutic cardiovascular procedures (Subcommittee on ambulatory electrocardiography). J Am Coll Cardiol 1989; 13: 249-258 